\title{
Transformation Superplasticity of Cast Titanium and Ti-6Al-4V
}

\author{
QIZHEN LI, EDWARD Y. CHEN, DOUGLAS R. BICE, and DAVID C. DUNAND
}

\begin{abstract}
Samples of unalloyed titanium and Ti-6Al-4V with a cast, coarse-grain structure were subjected to simultaneous mechanical loading and thermal cycling about their transformation range to assess their capability for transformation superplasticity. Under uniaxial tensile loading, high elongations to failure (511 pet for titanium, and 265 pct for Ti-6Al-4V) and an average strainrate sensitivity exponent of unity are observed. Samples previously deformed superplastically to a strain of 100 pct show no significant degradation in room-temperature mechanical properties as compared to the undeformed state. Biaxial dome bulging tests confirm that transformation superplasticity is activated under thermal cycling and faster than creep deformation. The cast, coarse-grained titanium and Ti-6Al-4V have similar transformation-superplasticity characteristics as wrought or powder-metallurgy materials with finer grains. This may enable superplastic forming of titanium objects directly after the casting step, thus bypassing the complicated and costly thermomechanical processing steps needed to achieve fine-grain superplasticity.
\end{abstract}

DOI: $10.1007 / \mathrm{s} 11661-006-9020-6$

(C) The Minerals, Metals \& Materials Society and ASM International 2007

\section{INTRODUCTION}

ONE approach to widen the application of titanium alloys is to reduce their processing cost by near-net-shape casting. ${ }^{[1]}$ However, in cast objects, an additional step such as machining is sometimes needed to achieve the final shape with the required tolerances. Superplastic forming is an attractive option, due to the low stresses needed for deformation and to the low tooling costs. ${ }^{[2]}$ However, in the as-cast state, titanium and most titanium alloys have a grain structure too coarse to allow deformation by grainboundary sliding through microstructural superplasticity, with the rare exception of multiphase intermetallic alloys that solidify with fine, equiaxed grains (e.g., TiAl- $\mathrm{Cr}^{[3]}$ ).

Thus, for most titanium alloys, and in particular for the commercially dominant Ti-6Al-4V alloy, complicated and costly thermomechanical treatments are needed to produce the fine grains with equiaxed shape necessary for microstructural superplasticity by grain-boundary sliding, resulting in high tensile strains ( $>100 \mathrm{pct}$ ) and low strain-rate sensitivity ${ }^{[4]}$ (we do not consider here high strains achievable in compression ${ }^{[5,6]}$ ). An alternative approach to achieve high tensile strains uses transformation superplasticity, which has no grain-size requirement because it relies on the biasing of internal stresses produced by cyclical phase transformation. ${ }^{[7]}$

A variety of polymorphic metals and alloys exhibit transformation superplasticity, including iron and steel, ${ }^{[7-13]}$ titanium and Ti alloys, ${ }^{[7,14-21]}$ zirconium and $\mathrm{Zr}$ alloys, ${ }^{[7,22-24]}$ cobalt, ${ }^{[7,25]}$ and uranium. ${ }^{[7,26,27]}$ Among these metals, titanium and its alloys are particularly

QIZHEN LI, Assistant Professor, is with the Department of Chemical and Metallurgical Engineering, University of Nevada, Reno, NV 89557, USA. DAVID C. DUNAND, Professor, is with the Department of Materials Science and Engineering, Northwestern University, Evanston, IL 60208, USA. Contact e-mail: dunand@northwestern.edu, EDWARD Y. CHEN and DOUGLAS R. BICE are with TiTech International, Inc., Orange, CA 92865, USA.

Mansucript submitted June 26, 2006. suitable for transformation superplasticity because they are commercially important and are difficult to shape by other methods. For the same reason, transformation superplasticity has interesting potential as a cost-effective forming process for low-ductility titanium composites (e.g., $\mathrm{Ti} / \mathrm{TiC}_{p},{ }^{[16,28,29]} \mathrm{Ti}-6 \mathrm{Al}-4 \mathrm{~V} / \mathrm{TiC}_{p},{ }^{[16,21]}$ and $\mathrm{Ti}-6 \mathrm{Al}-4 \mathrm{~V} / \mathrm{TiB}_{w}{ }^{[16,30,31]}$ ) and intermetallics (e.g., super- $\alpha_{2} \mathrm{Ti}_{3} \mathrm{Al}^{[32]}$ ).

All transformation superplasticity studies published so far on titanium and its alloys have been carried out on wrought or powder-metallurgy materials, which exhibit grain size and shapes inadequate for microstructural superplasticity. To date, there has been no demonstration of transformation superplasticity in titanium (or any other metal) in the as-cast state, where grains are typically much coarser than in the wrought or powdermetallurgy-densified state. The purpose of the present article is to demonstrate that transformation superplasticity can be achieved in as-cast titanium and Ti-6Al-4V, thus opening the possibility of a simplified process flow consisting of only two steps (casting and superplastic forming) to form objects into intricate shapes with close dimensional tolerances.

\section{MATERIALS AND EXPERIMENTAL PROCEDURES}

\section{A. Materials}

Both CP-Ti and Ti-6Al-4V were investment cast in two forms: bars (length: $200 \mathrm{~mm}$, diameter: $12.5 \mathrm{~mm}$ ) and plates $(150 \times 75 \times 6.4 \mathrm{~mm})$. Some samples were subsequently subjected to hot isostatic pressing (HIP) at $890{ }^{\circ} \mathrm{C}$ for 2 hours under a pressure of $105 \mathrm{MPa}$, a treatment commonly used to close casting porosity. For some Ti-6Al$4 \mathrm{~V}$ samples, the HIP treatment was followed by chemical milling to remove the alpha case, and then a mill-annealed heat treatment (HT) was carried out at $730{ }^{\circ} \mathrm{C} \pm 15{ }^{\circ} \mathrm{C}$ 
for 2 hours and terminated by furnace cooling. For comparison, wrought CP-Ti was also purchased in rod form from Alfa Aesar (99.6 pct pure) and in plate form from McMaster Carr (grade 2 CP-Ti, 99.4 pct pure).

For uniaxial superplasticity testing, cast bars were machined into cylindrical dog-bone samples with $20-\mathrm{mm}$ gage length and 4-mm gage diameter (or $7.5 \mathrm{~mm}$ for samples that were to be tested at ambient temperature after superplastic deformation). For biaxial superplasticity testing, disk specimens (62-mm diameter and approximately $1.5-\mathrm{mm}$ thickness) were machined from cast plates.

\section{B. Uniaxial Superplastic Testing}

Uniaxial transformation superplasticity experiments were conducted in a custom creep apparatus described in Reference 22, allowing for rapid thermal cycles under small tensile stresses and a flowing 99.999 pct pure argon atmosphere. The temperature was monitored by a Ktype thermocouple in contact with the sample gage. The temperature profile of the thermal cycles was triangular, with a lower temperature $T_{\min }=840{ }^{\circ} \mathrm{C}$ and upper temperatures $T_{\max }=940{ }^{\circ} \mathrm{C}$ for $\mathrm{CP}$-Ti (above the $\beta$ transus of $882^{\circ} \mathrm{C}$, for pure $\mathrm{Ti}$ ) and $T_{\max }=1030{ }^{\circ} \mathrm{C}$ for Ti-6Al-4V (above the $\beta$-transus of $995^{\circ} \mathrm{C}$ ).

To determine the stress sensitivity of the superplastic strain increment (defined here as the plastic strain accumulated over a complete thermal cycle), 4-min cycles were used for all CP-Ti samples and the as-cast Ti-6Al-4V samples, and 8-min cycles for the cast + HIP and cast + HIP + HT Ti-6Al-4V samples, with tensile stresses ranging between 0.5 and $6.5 \mathrm{MPa}$. Each sample was first heated to $T_{\max }$ and held until a steady-state creep rate was achieved at the lowest applied stress. Thereafter, the sample was subjected to five thermal cycles and the average strain increment per thermal cycle was calculated by averaging the last four measurements, with the standard deviation plotted as the error bar. The true stress was computed for each cycle under the assumption of uniform elongation and averaged, with the minimum and maximum values defining the error bar. The stress was then increased to a new value and the procedure was repeated. In a few cases, the stress was reduced to a prior lower value, to check for repeatability of the measurements.

To determine the effect of cycling rate upon superplastic strain increment per cycle, the stress level was maintained at a constant value of $0.5 \mathrm{MPa}$ and the duration of the cycle was varied between 2 and 18 minutes. The same procedure described previously for the stress-sensitivity tests was used.

For deformation to fracture tests, a cast + HIP CP-Ti and an as-cast Ti-6Al-4V sample were deformed under a constant 2.5 MPa stress with 4- and 8-min cycles, respectively. The sample was heated to $T_{\max }$, mechanically loaded, and then immediately subjected to thermal cycling (without first reaching steady-state creep at $\left.T_{\max }\right)$. To keep a constant stress level during the entire test, the load was adjusted frequently. The long test duration required some test interruptions, after which the sample was heated back to $T_{\max }$, loaded to the specified stress level, and immediately thermally cycled.
Three samples were deformed to an average engineering strain of 100 pct using the following stress and cycling periods: $2.5 \mathrm{MPa}$ and $4 \mathrm{~min}$ for as-cast CP-Ti, $2.0 \mathrm{MPa}$ and $4 \mathrm{~min}$ for cast + HIP CP-Ti, and $2 \mathrm{MPa}$ and $8 \mathrm{~min}$ for as-cast Ti-6Al-4V. As for fracture tests, the sample was mechanically loaded and subjected to thermal cycling immediately upon reaching $T_{\max }$. The stress was maintained near constant during the entire test by frequent adjustments of the load. After a 100 pct strain had been reached, the samples were cooled under stress and were remachined to a cylindrical gage length with diameter of approximately $4 \mathrm{~mm}$ and length of approximately $36 \mathrm{~mm}$ with threaded heads. These samples were then tested in tension at ambient temperature at a constant displacement rate of $1 \mathrm{~mm} / \mathrm{min}$ until fracture, using an extensometer to measure strain.

\section{Biaxial Superplastic Testing}

The equipment for biaxial doming experiments is similar to that used in Reference 16. The disk sample was clamped to an INCONEL* pressurization vessel

*INCONEL is a trademark of INCO Alloys International, Huntington WV.

resulting in an open-die diameter of $52 \mathrm{~mm}$ (larger than previous transformation superplasticity studies with diameters of $48^{[16]}$ and $36 \mathrm{~mm}^{[21]}$ ). The vessel/sample assembly was placed in a quartz tube under a flowing 99.999 pct pure argon atmosphere and heated by a radiant-area furnace positioned outside the quartz tube at a distance of about $70 \mathrm{~mm}$ above the disk. The temperature was controlled by a K-type thermocouple in contact with the disk surface. Before heating, the quartz tube and pressurization vessel were evacuated and flushed with argon several times, thus reducing contamination as compared to the previous procedures, ${ }^{[16]}$ when evacuation was not performed.

For CP-Ti and Ti-6Al-4V, the cycle temperatures and durations were the same as for uniaxial testing. The applied gas pressure was 200 and $250 \mathrm{kPa}$ above ambient pressure. At the beginning of each test, the sample was heated to $840{ }^{\circ} \mathrm{C}$, pressure was applied, and thermal cycling was initiated. At intervals of about 1 hour, the system was cooled to ambient temperature and the sample was checked visually. At the end of the test, the dome apex height was measured with a caliper; for two domes, the dome thickness was measured with a point micrometer on 31 points uniformly distributed along the projection of a half circle passing by the dome apex. Thickness measurements at equal distance from the dome apex but on opposite sides of the circles were averaged.

\section{RESULTS}

\section{A. Microstructure}

Micrographs of plate specimens in the as-cast and cast + HIP states are shown in Figures 1(a) through (d) 

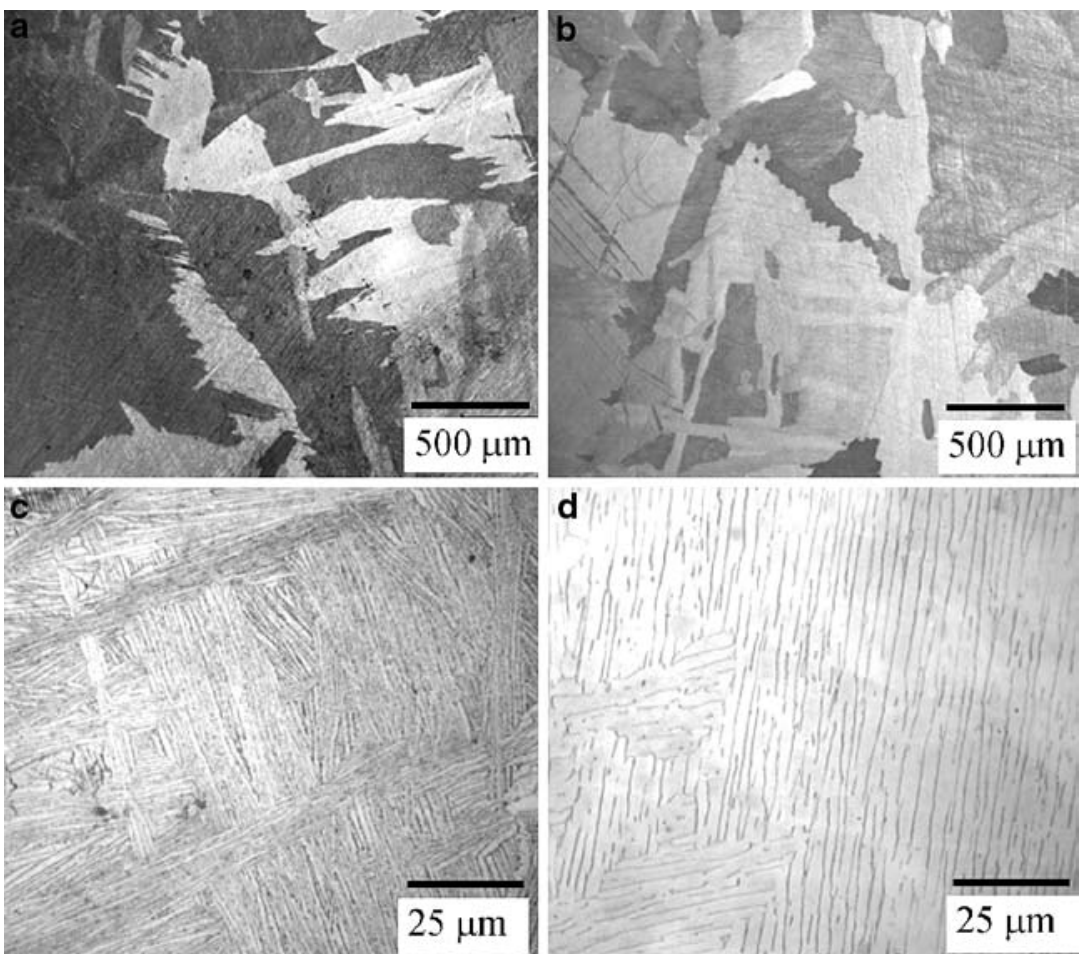

Fig. 1-Micrographs of plate specimens: $(a)$ as-cast CP-Ti, $(b)$ cast + HIP CP-Ti, $(c)$ as-cast Ti-6Al-4V, and $(d)$ cast + HIP Ti-6Al-4V.

for CP-Ti and Ti-6Al-4V etched with Kroll's and Keller's solution, respectively. Micrographs of bar specimens are similar and not shown here. As expected, the CP-Ti grain size is very coarse, in the range of $1 \mathrm{~mm}$ (Figure 1(a)). The HIP treatment does not appreciably change the grain size (Figure 1(b)). As-cast Ti-6Al-4V exhibits an elongated Widmannstätten structure typical of a cast and slow-cooled treatment (Figure 1(c)). After HIP, the $\alpha-\beta$ structure has coarsened (Figure 1(d)). Neither microstructure is amenable to microstructural superplasticity, which requires equiaxed grains with size below about $10 \mu \mathrm{m} \cdot{ }^{[4]}$

The chemical compositions of as-cast CP-Ti and Ti-6Al-4V samples are within limits set by the ASTM-B367-93 grade C-2 and AMS 4985B standards, respectively. In particular, the concentrations of hydrogen, carbon, nitrogen, and oxygen are $0.006,0.01,0.01$, and 0.19 wt pet, respectively, in both CP-Ti and Ti-6Al-4V, which are within the limits set by the preceding ASTM standard. Three separate CP-Ti and Ti-6Al-4V samples were analyzed chemically after 8 to 15 hours of superplastic testing and displayed a modest increase in nitrogen and oxygen to 0.02 and $0.25 \mathrm{wt}$ pet and a decrease in hydrogen to 0.002 to 0.003 wt pct, confirming that contamination was negligible during the experiments.

\section{B. Uniaxial Superplastic Testing}

A plot of average strain increment per cycle $v s$ applied tensile stress is given in Figure 2 for $\mathrm{CP}-\mathrm{Ti}$ in the as-cast and cast + HIP states and in Figure 3 for Ti-6Al-4V in the as-cast, cast + HIP, and cast + HIP + HT states.

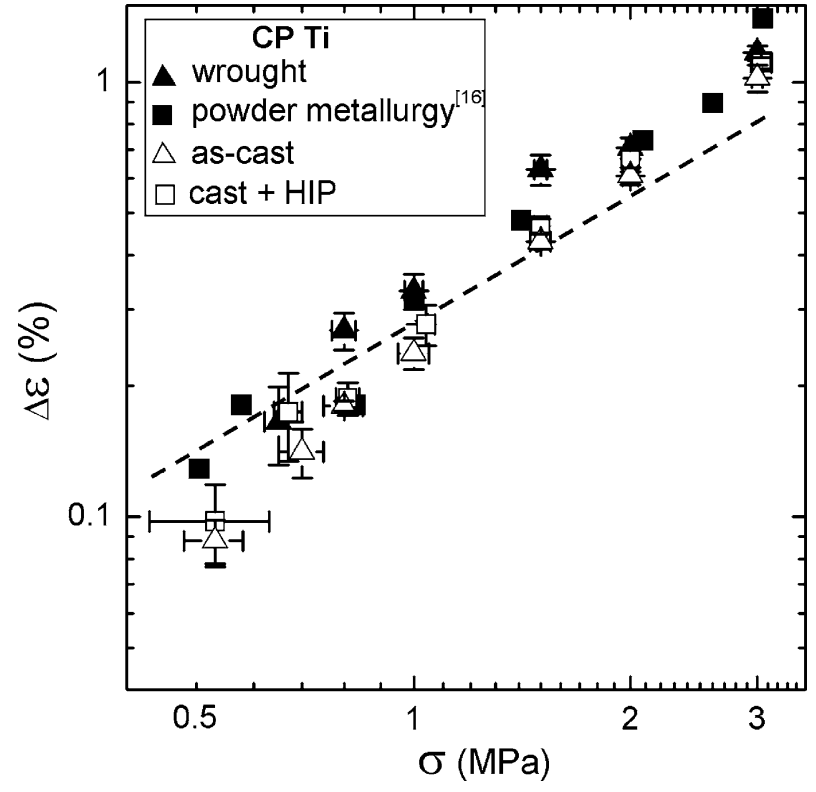

Fig. 2-Uniaxial strain increment per cycle $v s$ uniaxial applied stress for CP-Ti. Cycling conditions: $840{ }^{\circ} \mathrm{C}$ to $940{ }^{\circ} \mathrm{C}$, 4-min cycles for $\mathrm{CP}$-Ti (as-cast, cast $+\mathrm{HIP}$, wrought); $840{ }^{\circ} \mathrm{C}$ to $970{ }^{\circ} \mathrm{C}$, 4 -min cycles for CP-Ti (powder metallurgy). ${ }^{[16]}$ Line with slope of unity fits data well.

The plots are linear for low stress levels, corresponding to an average stress-sensitivity exponent of unity when cycling at a constant rate. There is no significant difference in the superplastic response between the cast, cast + HIP, and cast + HIP + HT states. 


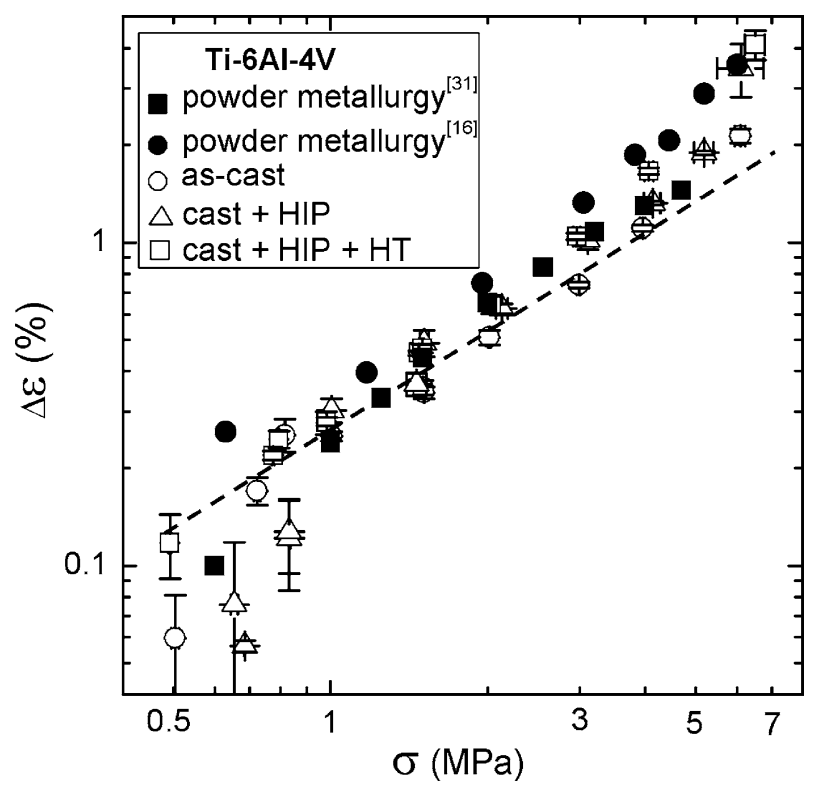

Fig. 3-Uniaxial strain increment per cycle $v s$ uniaxial applied stress for Ti-6Al-4V. Cycling conditions: $840^{\circ} \mathrm{C}$ to $1030{ }^{\circ} \mathrm{C}, 4$-min cycles for Ti-6Al-4V (as-cast); $840{ }^{\circ} \mathrm{C}$ to $1030{ }^{\circ} \mathrm{C}, 8$-min cycles for Ti-6Al$4 \mathrm{~V}$ (cast + HIP, cast + HIP + HT, powder metallurgy ${ }^{[16,31]}$ ). Line with slope of unity fits data well.

Figure 4 shows a cast + HIP CP-Ti sample before and after 100 pct engineering strain produced by transformation superplasticity at $2.0 \mathrm{MPa}$, and the same sample after remachining before and after room-temperature mechanical testing. Table I lists the mechanical properties obtained from room-temperature tensile tests on as-cast and cast + HIP CP-Ti and as-cast Ti-6Al-4V samples, all previously deformed to 100 pct strain by transformation superplasticity. There is no significant difference in the mechanical properties of the two CP-Ti

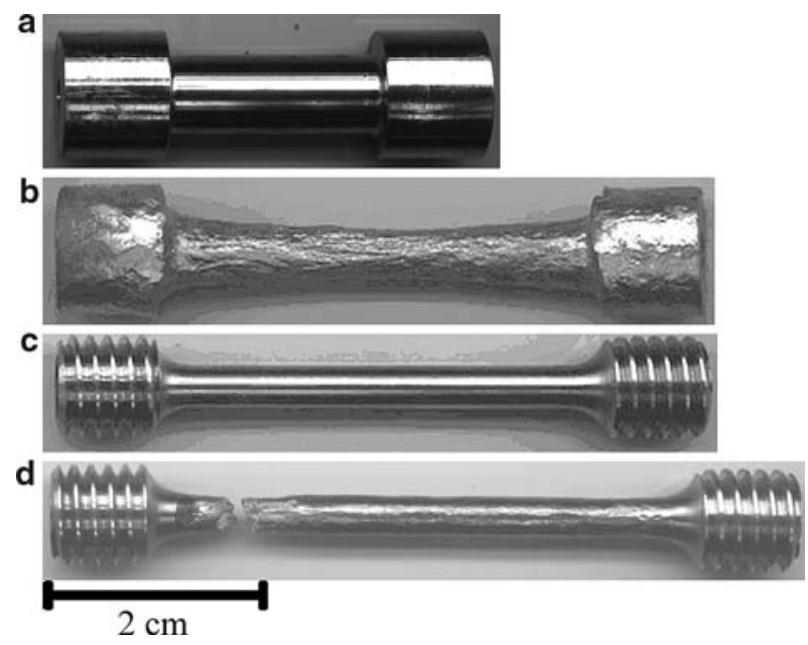

Fig. 4-Photographs of cast + HIP CP-Ti sample: $(a)$ before and (b) after $\sim 100$ pct elongation under thermal cycling conditions, (c) after remachining into a tensile sample, and (d) after subsequent tensile testing at room temperature.

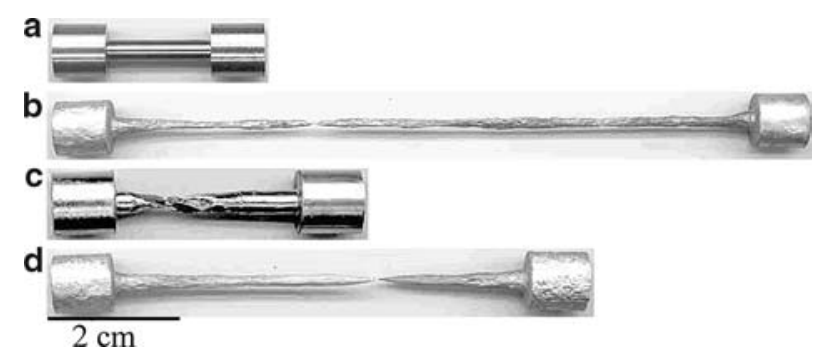

Fig. 5-Photographs of cast + HIP CP-Ti: $(a)$ before testing, $(b)$ after superplasticity fracture testing (511 pct elongation), and (c) after creep fracture testing (45 pct elongation). (d) Photographs of as-cast Ti-6Al-4V samples after superplasticity fracture testing (265 pct elongation).

samples. Comparison with literature values for cast materials also listed in Table I shows that the prior superplastic deformation results in a drop in strength (especially for CP-Ti) but an increase in ductility. Literature data for cast and annealed Ti-6Al-4V show nearly the same strength but higher elongation than the superplastically deformed sample.

Transformation superplasticity tests were carried out until specimen fracture on cast + HIP CP-Ti under a constant tensile stress of $2.5 \mathrm{MPa}$. The test was interrupted after 100 pct strain had been accumulated to check the surface condition: a slight oxide layer was observed and removed by polishing. The test was then resumed up to fracture, which occurred at an engineering strain of 511 pct, as illustrated in Figure 5. For comparison, an isothermal creep test was carried out on another cast + HIP CP-Ti sample at the maximum temperature of $940{ }^{\circ} \mathrm{C}$ (in the $\beta$ field) using the same applied stress. The elongation at fracture was only $\sim 45$ pct, as also illustrated in Figure 5. Finally, as-cast Ti-6Al-4V was also subjected to a superplasticity test

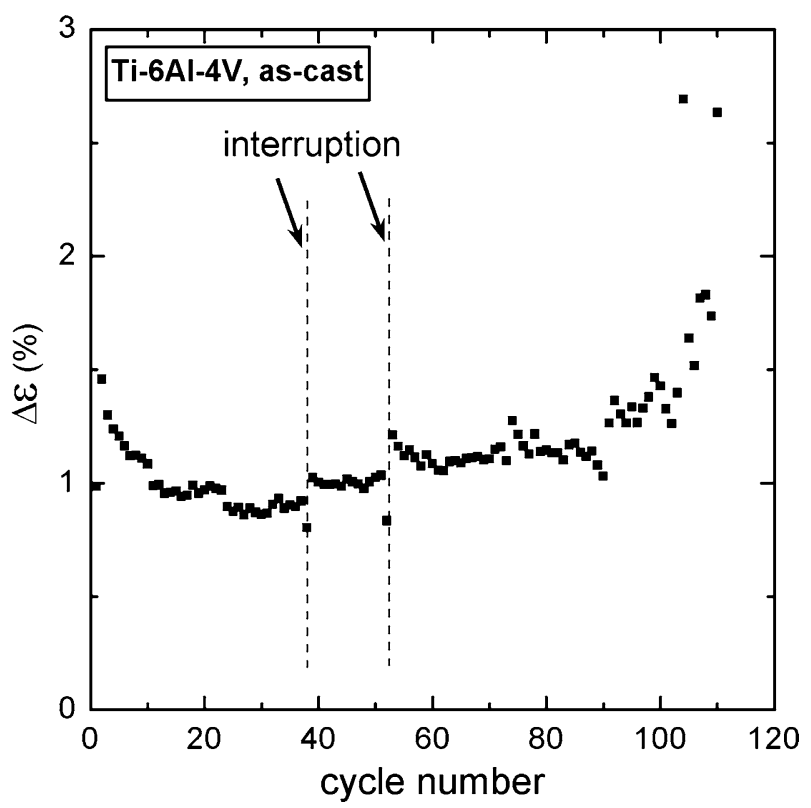

Fig. 6-Uniaxial strain increment per cycle vs cycle number for as-cast Ti-6Al-4V under $2.5 \mathrm{MPa}$ uniaxial applied stress. 
Table I. Mechanical Properties Measured on Samples Previously Deformed to 100 Pct Engineering Strain by Transformation Superplasticity; Literature Data Are Also Listed for Cast CP-Ti and Ti-6Al-4V without Prior Deformation

\begin{tabular}{|c|c|c|c|c|c|}
\hline Treatment & $\begin{array}{c}\text { Young's } \\
\text { Modulus (GPa) }\end{array}$ & $\begin{array}{l}\text { Yield Strength } \\
(\mathrm{MPa})\end{array}$ & $\begin{array}{l}\text { Ultimate Tensile } \\
\text { Strength }(\mathrm{MPa})\end{array}$ & $\begin{array}{l}\text { Elongation } \\
\text { (Pct) }\end{array}$ & $\begin{array}{c}\text { Reduction of } \\
\text { Area (Pct) }\end{array}$ \\
\hline \multicolumn{6}{|l|}{ CP-Ti } \\
\hline As-cast, 100 pet strain & 113 & 365 & 456 & 21.5 & 43 \\
\hline Cast + HIP, 100 pet strain & 106 & 361 & 447 & 20 & 37 \\
\hline Cast, machined (grade 2$)^{[35,36]}$ & 103 to 107 & 448 & 552 & 18 & 32 \\
\hline \multicolumn{6}{|l|}{ Ti-6Al-4V } \\
\hline As-cast, 100 pet strain & 116 & 835 & 924 & 7.6 & 22 \\
\hline $\mathrm{Cast}^{[36]}$ & 105 to 116 & 896 & 1000 & 8 & 16 \\
\hline Cast $+\mathrm{HIP}^{[36]}$ & 105 to 116 & 869 & 958 & 10 & 18 \\
\hline Cast, machined, annealed ${ }^{[36]}$ & - & 855 & 930 & 12 & 20 \\
\hline
\end{tabular}

under the same stress and achieved an elongation of 265 pct at fracture, as shown in Figure 5.

For as-cast Ti-6Al-4V, the evolution of the strain increment per cycle is shown in Figure 6 and consists of three regions: (1) a short primary region lasting about 10 cycles, where the strain increments decrease; (2) a long secondary region, where the strain increments are constant; and (3) a short tertiary stage, where the strain increments increase, spanning the last 20 cycles and probably corresponding to sample necking. The test was interrupted twice, as marked in Figure 6. A short primary region lasting about five cycles follows each interruption. For the secondary region, the ratio of strain increment to applied stress is about $4 \mathrm{GPa}^{-1}$, which is consistent with results from the stress-sensitivity tests (Figure 3).

Finally, Figure 7 shows, for as-cast and cast + HIP $\mathrm{CP}-\mathrm{Ti}$, the strain increment per cycle as a function of the cycle period for a constant applied stress of $0.5 \mathrm{MPa}$.

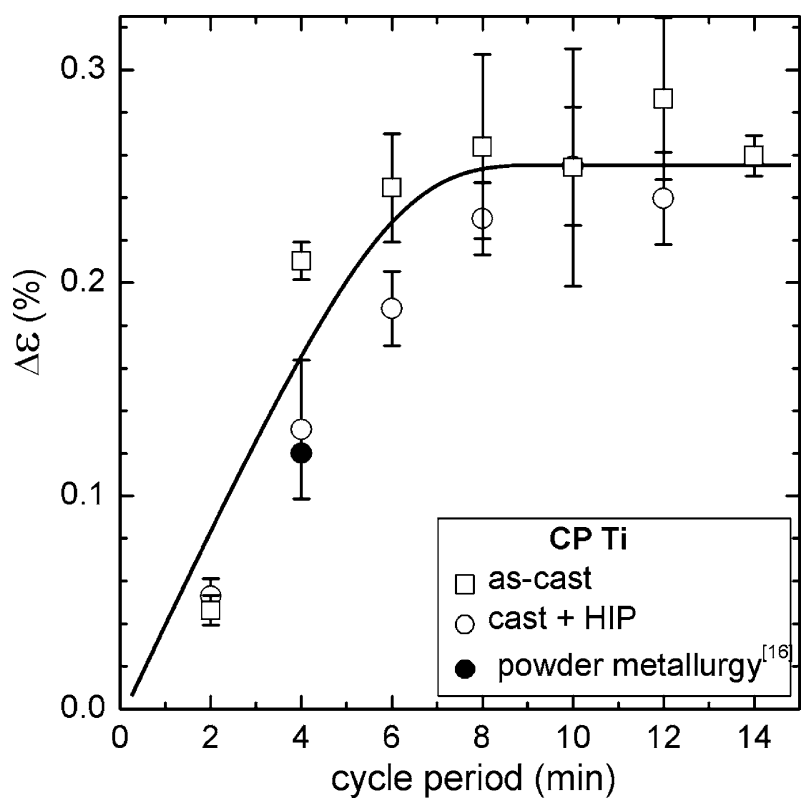

Fig. 7-Uniaxial strain increment per cycle $v s$ cycle period for CP-Ti under uniaxial stress of $0.5 \mathrm{MPa}$. Cycling conditions: $840{ }^{\circ} \mathrm{C}$ to $940{ }^{\circ} \mathrm{C}$ for as-cast and cast + HIP CP-Ti; $840{ }^{\circ} \mathrm{C}$ to $970{ }^{\circ} \mathrm{C}$ for powder-metallurgy CP-Ti. ${ }^{[16]}$
The strain increment first increases linearly with the period and then becomes constant for periods in excess of about 6 minutes. Figure 8 shows the corresponding data for as-cast and cast + HIP Ti-6Al-4V. Here, for the cast + HIP state, the strain increment increases nearly linearly up to a 10-minute period before becoming constant. For the as-cast state, the strain increments are somewhat larger at a given stress and do not stabilize to a constant value, even at the longest period of 14 minutes.

\section{Biaxial Superplastic Testing}

Five biaxial doming experiments were carried out, as summarized in Table II. One experiment was performed on cast + HIP CP-Ti until fracture, under a gas pressure of $200 \mathrm{kPa}$. The dome deformed for 60 cycles beyond the hemisphere shape, as shown in Figure 9. The final apex thickness $s_{f}$ was lower by a factor 4.2 as compared to the original disk thickness $s_{o}$, resulting in

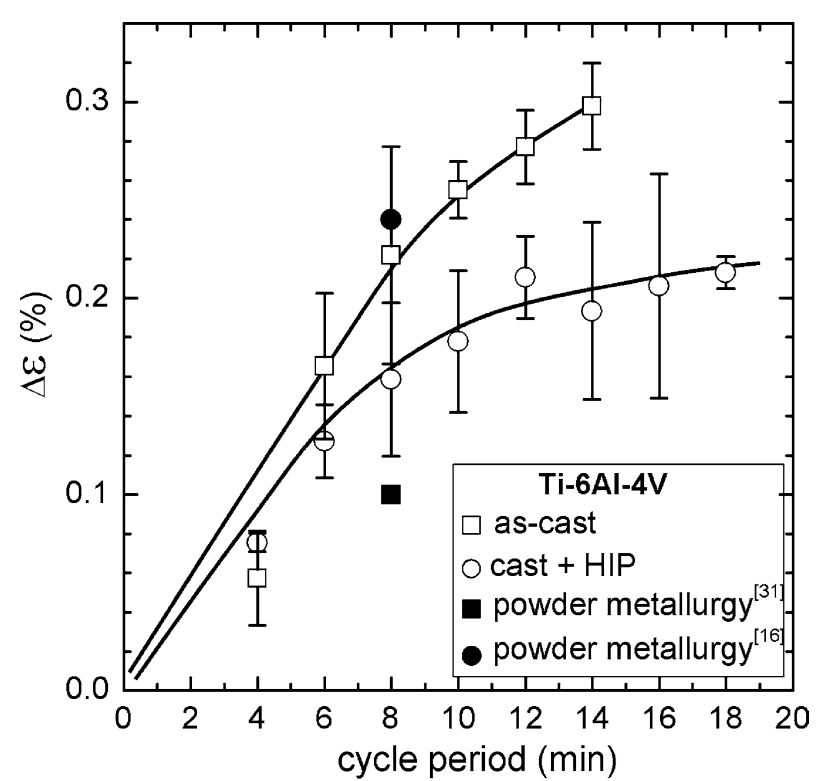

Fig. 8-Uniaxial strain increment per cycle $v s$ cycle period for Ti6Al-4V under uniaxial applied stress of $0.5 \mathrm{MPa}$. Cycling conditions: $840{ }^{\circ} \mathrm{C}$ to $1030{ }^{\circ} \mathrm{C}$ for as-cast, cast $+\mathrm{HIP}$ Ti-6Al-4V, and powdermetallurgy Ti-6Al-4V. ${ }^{[16,31]}$ 
Table II. Summary of Experimental and Modeling Results for Biaxial Doming Experiments

\begin{tabular}{|c|c|c|c|c|c|c|c|c|c|c|}
\hline Sample & $\begin{array}{c}\text { Gas } \\
\text { Pressure, } \\
p(\mathrm{kPa})\end{array}$ & $\begin{array}{l}\text { Number of } \\
\text { Cycles }(-)\end{array}$ & $\begin{array}{l}\text { Testing } \\
\text { Time } \\
\text { (min) }\end{array}$ & $\begin{array}{l}\text { Original } \\
\text { Disk } \\
\text { Thickness, } \\
S_{o}(\mathrm{~mm})\end{array}$ & $\begin{array}{c}\text { Apex } \\
\text { Thickness } \\
(\mathrm{mm})\end{array}$ & $\begin{array}{c}\text { Apex } \\
\text { Effective } \\
\text { Strain } \\
\text { (Measured) } \\
(-)\end{array}$ & $\begin{array}{l}\text { Apex } \\
\text { Effective } \\
\text { Strain } \\
\text { (from } \\
\text { Eq. [6]) }\end{array}$ & $\begin{array}{c}\text { Apex } \\
\text { Height, } h \\
\text { (Measured) } \\
\text { (mm) }\end{array}$ & $\begin{array}{l}\text { Apex } \\
\text { Height } \\
\text { (from } \\
\text { Eq. [2]) } \\
\text { (mm) }\end{array}$ & $\begin{array}{l}\text { Dome } \\
\text { Shown in } \\
\text { Figure }\end{array}$ \\
\hline \multicolumn{11}{|c|}{ Superplastic experiments } \\
\hline CP-Ti (cast + HIP) & 200 & 60 & 240 & 1.53 & 0.37 & $1.42^{*}$ & ** & 19.7 & ** & 9 \\
\hline $\begin{array}{l}\text { Ti-6Al-4V } \\
(\text { cast }+ \text { HIP }+ \text { HT })\end{array}$ & 200 & 25 & 200 & 1.53 & 1.11 & 0.32 & 0.49 & 13.6 & 10.5 to 11.4 & - \\
\hline Ti-6Al-4V (as-cast) & 200 & 98 & 784 & 1.54 & 0.69 & 0.80 & 0.82 & 18.3 & 20.2 to 23.3 & 10 \\
\hline Ti-6Al-4V (as-cast) & 250 & 32 & 256 & 1.56 & 0.74 & 0.75 & 0.60 & 15.6 & 12.8 to 14.0 & $11(\mathrm{a})$ \\
\hline Creep experiment & & & & & & & & & & \\
\hline Ti-6Al-4V (as-cast) & 250 & $\dagger$ & 256 & 1.55 & 1.22 & 0.24 & 0.28 & 9.96 & 7.5 to 7.9 & $11(b)$ \\
\hline
\end{tabular}

* Only dome deformed to fracture.

${ }^{* *}$ Not calculated, because dome is not hemispherical.

${ }^{\dagger}$ A single cycle, consisting of initial and final ramping between ambient and creep temperature of $990{ }^{\circ} \mathrm{C}$.

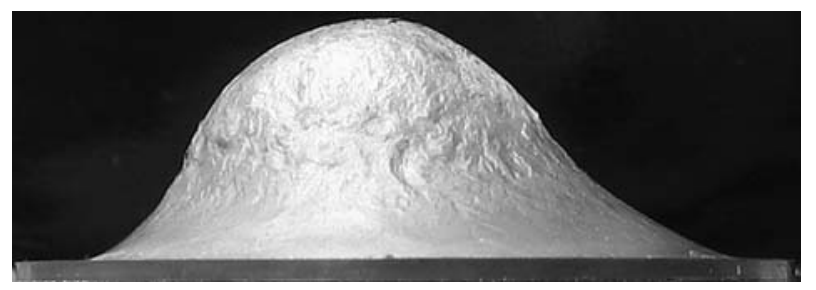

Fig. 9-Photograph of cast + HIP CP-Ti dome deformed to fracture by thermal cycling (60 cycles) under $200 \mathrm{kPa}$ gas pressure (apex height: $19.7 \mathrm{~mm}$ ).

an effective von Mises strain $e=\ln \left(s_{o} / s_{f}\right)=1.42$ at the apex. This value is well in excess of the true strain value of 0.69 , which corresponds to an engineering strain of 100 pct in uniaxial tension and is usually taken as the minimum value for superplasticity.

The remaining four experiments were carried out on Ti-6Al-4V. Two domes were deformed under a pressure of $200 \mathrm{kPa}$ for 25 and 98 cycles, in the cast + HIP + HT and as-cast states, respectively. The latter dome, with an effective apex strain of 0.80 , is depicted in Figure 10. Two other as-cast Ti-6Al-4V domes were tested under the same higher gas pressure of $250 \mathrm{kPa}$, one under transformation superplasticity conditions and the other under isothermal creep conditions at $990{ }^{\circ} \mathrm{C}$, for the same total testing time of 256 minutes. These domes are depicted in Figures 11(a) and (b), which demonstrate the much more rapid deformation achieved

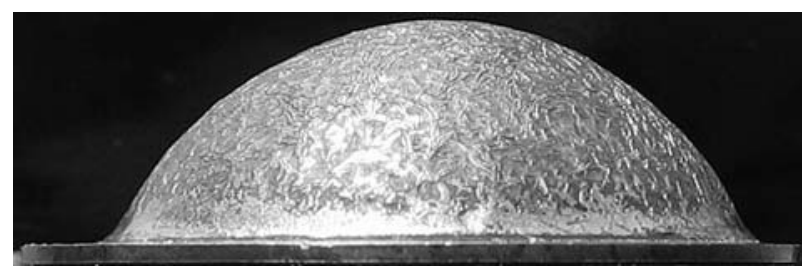

Fig. 10 - Photograph of as-cast Ti-6Al-4V dome deformed by thermal cycling (98 cycles) under $200 \mathrm{kPa}$ gas pressure (apex height: $18.3 \mathrm{~mm}$ ).
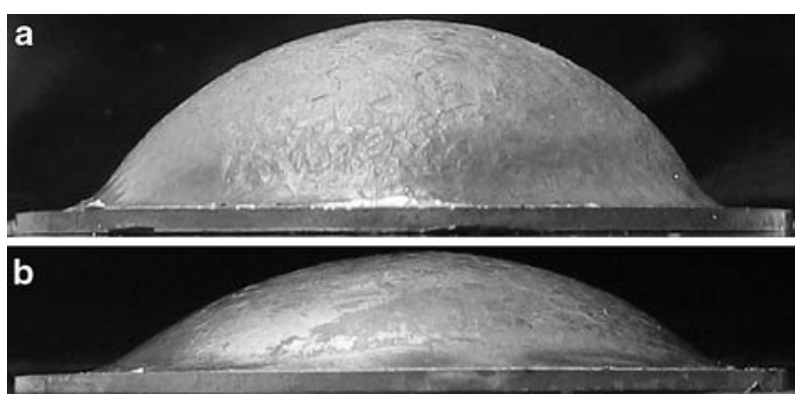

Fig. 11-Photographs of as-cast Ti-6Al-4V domes deformed under $250 \mathrm{kPa}$ gas pressure for the same time of $256 \mathrm{~min}$ : (a) superplastic deformation after 32 thermal cycles (apex height: $15.6 \mathrm{~mm}$ ); and $(b)$ creep deformation at constant temperature of $990{ }^{\circ} \mathrm{C}$ (apex height: $9.96 \mathrm{~mm})$.

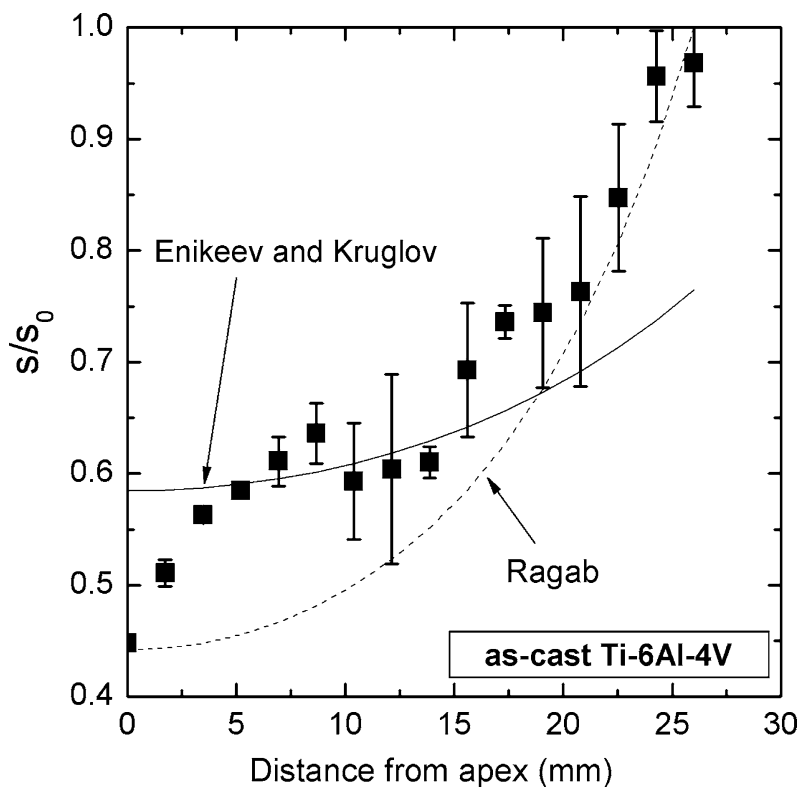

Fig. 12-Profile of dome thickness (normalized by original thickness) showing experimental data for the as-cast Ti-6Al-4V dome after 98 cycles (shown in Fig. 10), and predictions from the models of Enikeev and Kruglov ${ }^{[33]}$ (Eq. [5]) and Ragab ${ }^{[34]}$ (Eq. [6]). 
under superplastic cycling conditions. As expected, the apex strain of the superplastically deformed dome, 0.75 , is much higher than that for the creep-deformed dome, 0.24 .

The thickness distribution is measured for the as-cast Ti-6Al-4V dome (shown in Figure 10) and is plotted in Figure 12. Within experimental error, the thickness increases monotonically from the dome apex to its circumference, as expected from the biaxial state of stress present during deformation. ${ }^{[33,34]}$

\section{DISCUSSION}

\section{A. Uniaxial Superplastic Testing}

1. Strain increments during thermal cycling

As shown in Figure 2 for as-cast and cast + HIP CP$\mathrm{Ti}$, the strain per cycle $\Delta \varepsilon$ increases linearly with stress $\sigma$, in agreement with the transformation superplasticity theory of Greenwood and Johnson: ${ }^{[26]}$

$$
\Delta \varepsilon \approx \frac{4}{3} \cdot \frac{\Delta V}{V} \cdot \frac{5 \cdot n}{4 \cdot n+1} \cdot \frac{\sigma}{\sigma_{o}}
$$

where $\Delta V / V$ is the volume mismatch between the allotropic phases; $n$ is the creep stress exponent of the phase which accommodates the mismatch strain $(\beta$-Ti); and $\sigma_{o}$ is the time- and volume-averaged internal equivalent stress during the phase transformation. The slope of our data in Figure 2, when plotted linearly, is $4.0 \mathrm{GPa}^{-1}$, which is somewhat higher than the slope of 2.3 to $2.9 \mathrm{GPa}^{-1}$ reported by Schuh and Dunand ${ }^{[29]}$ and Frary et al. ${ }^{[16]}$ on powder-metallurgy CP-Ti tested over a broader stress interval and with a higher maximum temperature $\left(T_{\max }=970{ }^{\circ} \mathrm{C}\right.$ to $\left.1030{ }^{\circ} \mathrm{C}\right)$. The measurements by Frary et al. ${ }^{[16]}$ are shown in Figure 2 up to a stress of $3 \mathrm{MPa}$ and are within the experimental error of our measurements. Also shown in Figure 2 are our results for wrought $\mathrm{CP}-\mathrm{Ti}$, which are undistinguishable from those for the cast CP-Ti. Thus, CP-Ti processed by various routes (investment cast, wrought, and powdermetallurgy processed) shows the same transformation superplasticity behavior, independently of grain size.

The same general conclusion can be reached for Ti-6Al-4V (Figure 3): there is no significant difference between the three states (as-cast, cast + HIP and cast + HIP + HT), despite the shorter cycling period for the former material, up to a stress of $6 \mathrm{MPa}$. There is good agreement with powder-metallurgy Ti-6Al-4V reported by Frary et al. ${ }^{[16]}$ and Schuh and Dunand ${ }^{[30]}$ (with the same temperature range and cycling period of $8 \mathrm{~min}-$ utes). The average slope of our data for all three states is $3.8 \mathrm{GPa}^{-1}$ in linear plots, within the range of values reported by References 18, 19, and 30 (2.1 to $4.0 \mathrm{GPa}^{-1}$ ). Equation [1], which was developed for pure metals with a single transformation temperature, also holds for alloys with a transformation temperature range. ${ }^{[19]}$

As shown in Figure 7, a linear relationship exists between strain per cycle and cycling period up to periods of 4 to 6 minutes, and our data are in good agreement with a data point for powder-metallurgy CP-Ti tested for a stress of $\sim 0.5 \mathrm{MPa}$ and a 4-minute period at slightly different temperatures $\left(840{ }^{\circ} \mathrm{C}\right.$ to $\left.970{ }^{\circ} \mathrm{C}\right)$ by Frary et al..$^{[16]}$ This linear regime can be interpreted as due to incomplete sample transformation (due to heat transfer and transformation kinetics limitations), producing a reduced strain increment, as seen from the factor $\Delta V / V$ in Eq. [1] and as discussed in more detail in Reference 19. In this linear regime, the average strain rate under continuous cycling is constant: slower cycling provides fewer transformation events, but more strain per event. For longer cycling periods beyond 4 to 6 minutes, the strain increment is independent of the cycle period, as expected if transformation occurs in the entire volume of the sample (Eq. [1]). Here, the average strain rate decreases with longer cycling period. For very long periods, the creep contribution to strain is expected to become dominant, leading to an increase in strain per cycle, but this regime is not reached in Figure 7 for the longest measured period of 14 minutes, probably because of the low stress of $0.5 \mathrm{MPa}$ used here.

The cycle-period dependence of strain for cast + HIP Ti-6Al-4V, shown in Figure 8, is qualitatively the same as for CP-Ti in Figure 7, except for the extension of the near-linear range to a longer period of 8 to 10 minutes. This difference is likely due to the more sluggish transformation kinetics of Ti-6Al-4V as compared to $\mathrm{CP}-\mathrm{Ti}$. For as-cast Ti-6Al-4V, the strain increment does not stabilize up to the longest period of 14 minutes. This may be due to a larger contribution from creep as a result of the change in microstructure (Figures 1(c) and (d)). However, the differences between as-cast and cast + HIP curves in Figure 8 may not be significant, given that the measured strain increments for 8-minute cycles are within the range measured for powder-metallurgy Ti-6Al-4V, tested at a slightly higher stress of $\sim 0.6 \mathrm{MPa}$ by Frary et al ${ }^{[16]}$ and Schuh and Dunand ${ }^{[30]}$ in the same temperature range.

\section{Damage and fracture}

Results shown in Table I demonstrate that, for a sample previously deformed to an engineering strain of 100 pct through transformation superplasticity, strength is somewhat lower, but ductility is somewhat higher, than the literature data on cast materials. The drop in strength may reflect the relatively low interstitial content of the materials, while the high ductilities indicate that microstructural damage, including cavitation, is absent. This is consistent with a previous study ${ }^{[18]}$ in which very little or no cavitation was measured in powder-metallurgy Ti-6Al-4V deformed uniaxially to tensile strains up to 270 pct. To our knowledge, there has been no prior measurement of mechanical properties after deformation by transformation superplasticity, so the present results demonstrate for the first time that this forming process does not adversely affect ambient-temperature mechanical properties (strength could be easily boosted by an intentional increase in interstitials during casting or superplastic forming).

The uniaxial strain of 511 pct achieved in cast + HIP CP-Ti by transformation superplasticity (Figure 5) is higher than the value of 200 pct reported previously for $\mathrm{CP}-\mathrm{Ti},{ }^{[28]}$ which was however probably lowered by the presence of gas entrapped within the material. ${ }^{[29]}$ 
Similarly, the fracture strain of 265 pct measured here for as-cast Ti-6Al-4V (Figure 5) is comparable to the values of $275 \mathrm{pct}^{[18]}$ but lower than the value of $398 \mathrm{pct}^{[31]}$ for Ti-6Al-4V produced by powder metallurgy. Thus, for superplastic ductility too, there seems to be no systematic effect of grain size, as expected.

\section{B. Biaxial Superplastic Testing}

\section{Apex effective strain and apex height}

As reported in Table II, the apex effective strains for three of the superplastically deformed domes are in excess of the minimal superplastic value of 0.69 , giving direct evidence of superplasticity in cast, coarse-grained CP-Ti and Ti-6Al-4V. Similarly, an apex effective strain $e=2.6$ was measured previously for a powder-metallurgy Ti-6Al-4V dome deformed to fracture by thermal cycling $^{[21]}$ and was found to be much larger than the fracture strain $e=0.32$ achieved by isothermal deformation by creep. Frary et al. ${ }^{[16]}$ also conducted biaxial dome formation of powder-metallurgy $\mathrm{CP}-\mathrm{Ti}$ and $\mathrm{Ti}-$ $6 \mathrm{Al}-4 \mathrm{~V}$ by transformation superplasticity and found much higher bulging rates as compared with isothermal control experiments. Similarly, for the two dome bulging tests on cast Ti-6Al-4V carried out for the same duration and with the same applied gas pressure, it is apparent that the dome thermally cycled between $840{ }^{\circ} \mathrm{C}$ and $1030{ }^{\circ} \mathrm{C}$ achieves a much higher apex strain $(e=0.75)$ than the one crept isothermally at $990{ }^{\circ} \mathrm{C}(e$ $=0.24$ ), as illustrated in Figures 11(a) and (b). This temperature is close to the effective temperature of $982^{\circ} \mathrm{C},{ }^{[18]}$ at which deformation rates are the same in the absence of transformation superplasticity, providing further evidence that transformation superplasticity is the dominant deformation mechanism during thermal cycling.

The nondimensional dome apex heights $\eta$ (defined as the apex height $h$ divided by the disk radius $b$ before bulging) can be calculated using equations developed by Frary et al., ${ }^{[16]}$ based on the work of Enikeev and Kruglov, ${ }^{[33]}$ as

$$
\dot{\eta}=\frac{1}{2} \cdot \frac{\eta \cdot \arctan \eta \cdot\left(1+\eta^{2}\right)}{\eta-\arctan \eta \cdot\left(1-\eta^{2}\right)} \cdot\left[K_{\text {creep }} \cdot S^{n}+K_{\mathrm{TSP}} \cdot S\right]
$$

where $K_{\text {creep }}$ and $K_{\text {TSP }}$ are the creep and superplastic constants relating the uniaxial strain rate $\dot{\varepsilon}$ with the uniaxial stress $\sigma$ through the power-law equations:

$$
\begin{gathered}
\dot{\varepsilon}_{\text {creep }}=K_{\text {creep }} \cdot \sigma^{n} \\
\dot{\varepsilon}_{\mathrm{TSP}}=K_{\mathrm{TSP}} \cdot \sigma
\end{gathered}
$$

where $n$ is the creep stress exponent $(n=1$ for transformation superplasticity, Figures 2 and 3). In Eq. [2], the stress $S$ is defined as

$$
S=\frac{p b}{4 s_{o}} \cdot \frac{\arctan ^{2} \eta \cdot\left(1+\eta^{2}\right)^{3}}{\eta^{3}}
$$

where $p$ is the gas pressure and $s_{o}$ is the original sheet thickness.
Equation [2] is a differential equation that relates the rate of change in the dome height to the dome instantaneous height, as a function of forming pressure, geometric parameters (initial sheet thickness and radius), and deformation parameters for isothermal creep

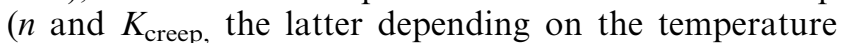
range spanned during cycling) and transformation superplasticity ( $K_{\mathrm{TSP}}$, which depends on the cycling period). Equation [2] was numerically evaluated using creep and superplastic parameters determined from uniaxial experiments, as done in Reference 16. Transformation superplasticity is assumed to take place between $840{ }^{\circ} \mathrm{C}$ and $995^{\circ} \mathrm{C}$, with a superplastic constant $K_{\mathrm{TSP}}=4.4 .10^{-12} \mathrm{~Pa}^{-1} \cdot \mathrm{s}^{-1} \cdot{ }^{[15]}$ For the cycle range between $995{ }^{\circ} \mathrm{C}$ and $1030^{\circ} \mathrm{C}$, when Ti-6Al-4V is in the $\beta$-field, creep is taken to occur with a stress exponent $n=2.8^{[19]}$ The effective value of the creep constant for Ti-6Al-4V, averaged over the entire cycle duration, is $K_{\text {creep }}=3.7 .10^{-25} \mathrm{~Pa}^{-2.8} \cdot \mathrm{s}^{-1}$, calculated by averaging experimental creep data for $\beta$-Ti-6Al- $4 \mathrm{~V}^{[18]}$ between $995{ }^{\circ} \mathrm{C}$ and $1030{ }^{\circ} \mathrm{C}$. Ranges of apex heights predicted from Eq. [2], assuming an uncertainty of 10 pct on the creep and superplastic constants, are listed in Table II for the three superplastically and the single creepdeformed Ti-6Al-4V domes. The calculated apex height can be considered to be in reasonable agreement with experimental data, given the many uncertainties associated with materials parameters (in particular with the creep parameters) and the numerous possible sources of experimental errors.

\section{Dome thickness distribution}

The measured thickness distribution for superplastically deformed domes can be predicted based on two models. The first model, developed by Enikeev and Kruglov, ${ }^{[33]}$ assumes that each meridian passing through the dome apex is uniformly deformed at any point in time and that the stress state appropriately varies from balanced biaxial at the apex to plane strain at the dome periphery. This model leads to the following equation for the variation in dome thickness $s:{ }^{[16]}$

$$
s=s_{o} \cdot\left(\frac{\sin \alpha}{\alpha}\right)^{2} \cdot \frac{\theta}{\sin \theta}
$$

where $\alpha$ is the angle subtended by the apex and the edge of the dome (thus describing the dome radius of curvature), and position is given by the angle $\theta$, which varies between $\theta=0$ at the dome apex and $\theta=\alpha$ at the dome periphery. The other thickness-distribution model by Ragab ${ }^{[34]}$ assumes a balanced biaxial stress state throughout the dome. The thickness for any point on the dome is ${ }^{[16]}$

$$
s=s_{o} \cdot\left(\frac{\cos \alpha+1}{\cos \theta+1}\right)^{2}
$$

Predictions for both models, using a value of the angle $\alpha$ measured by fitting a circle to the dome profiles, are plotted in Figure 12; it is apparent that the EnikeevKruglov model predicts more uniform deformation across the Ti-6Al-4V dome surface than the measured 
data or the prediction of the Ragab model. The latter model fits reasonably well the experimental data in Figure 12 (with apex effective strain $e=0.80$ ), as well as another profile (not shown here) measured for the cast + HIP + HT Ti-6Al-4V dome with an apex effective strain $e=0.32$ (Table II). The quality of the fit between measured and calculated profiles is similar to that shown by Frary et al. ${ }^{[16]}$ for powder-metallurgy CP$\mathrm{Ti}$ and Ti-6Al-4V domes deformed by transformation superplasticity to similar apex strains $e=0.78$ and 0.46 , respectively. Also, as shown in Table II, the apex effective strain predicted from Ragab's model (Eq. [6]) is in general agreement with the measured values for all Ti-6Al-4V domes.

As discussed by Frary et al., ${ }^{[16]}$ deviations from the model may be due to lower average temperatures at the dome periphery as compared to the apex, leading to a reduced span of temperature cycling and thus lower superplastic strain increments. Three sources were identified for this temperature gradient: leak of pressurization gas, cooling preferentially the dome periphery; the heat-sink effect from the pressurization vessel being more pronounced at the periphery; and the lower radiation absorption at the periphery due to steeper angle of dome and larger distance from heat source.

\section{Manufacturing Implications}

The results reported here unequivocally demonstrate that transformation superplasticity can be achieved in CP-Ti and Ti-6Al-4V in the as-cast state (with or without additional densification or heat-treatment steps) with grain sizes and shapes incompatible with isothermal microstructural superplasticity. It may thus be possible to superplastically deform intricate cast objects by gas pressure or through a piston, thus significantly simplifying the traditional process flow using microstructural superplasticity (billet casting, sheet fabrication by rolling or forging, thermomechanical processing to achieve a fine grain size, and superplastic forming at constant temperature). Simple cast shapes (rods, plates, and tubes) could also be superplastically formed into much more complex shapes with an attendant reduction in wall thickness, which is also interesting given that cast wall thicknesses are limited by titanium's low fluidity and high reactivity with the mold. However, rapid thermal cycling is experimentally more difficult to achieve than isothermal conditions.

One important issue not studied here is the effect on transformation superplasticity of the alpha case usually present at the surface of cast titanium objects as a result of reaction with the mold. The alpha case is not expected to transform at temperatures where the rest of the casting does, and may thus impede superplastic deformation and promote early failure. In the present investigation, the alpha case was removed during machining of the samples, because the goal was to study the effect of the large cast grain size. In industrial practice, it may be necessary to remove the alpha case by chemical milling, a common and relatively inexpensive step for titanium castings. Alternatively, the alpha case may be able to deform cooperatively with the underlying transforming alloy, so its presence may be tolerated during superplastic forming.

Finally, we note that the current results on cast $\mathrm{CP}-\mathrm{Ti}$ and $\mathrm{Ti}-6 \mathrm{Al}-4 \mathrm{~V}$ are a strong indication that other allotropic metals and alloys (other Ti alloys as well as Fe-, Co-, Zr-, and U-based alloys) and composites can be superplastically deformed in the as-cast state as well.

\section{CONCLUSIONS}

Cast, coarse-grain CP-Ti and Ti-6Al-4V are shown to exhibit transformation superplasticity under thermal cycling conditions. To the best of our knowledge, this is the first demonstration of superplasticity in cast titanium and its alloys, and may lead to significant savings in processing costs for complex shapes.

The following conclusions can be reached based on uniaxial tensile tests.

1. At low applied stresses, a linear relationship between the strain increment per cycle and applied stress is observed for as-cast CP-Ti and Ti-6Al-4V with and without subsequent HIP or heat-treatment steps, corresponding to an average strain-rate sensitivity of unity. Tensile strains well over 200 pct are achieved under thermal cycling.

2. With increasing cycling periods, the average strain rate during thermal cycling is at first constant for short periods and decreases for longer periods due to a reduced contribution of transformation superplasticity.

3. Ambient-temperature tensile properties are not significantly affected by a prior superplastic deformation step to an engineering strain of 100 pct by transformation superplasticity, indicating lack of cavitation or damage during superplastic deformation.

Biaxial doming experiments lead to the following conclusions.

1. The effective tensile strain at the apex of thermally cycled domes reaches values well in excess of 100 pct engineering strain.

2. Transformation superplasticity leads to much faster biaxial deformation rates than isothermal creep.

3. The dome apex height can be predicted using models considering the contribution of both transformation superplasticity and creep during the cycles.

4. Existing dome thickness distribution models are in reasonable agreement with measured data.

\section{ACKNOWLEDGMENTS}

This study was funded by the National Science Foundation through Award No. DMI-0420083. The authors acknowledge Mr. R. Scheunemann (Northwestern University) for help in metallographic preparation. 


\section{REFERENCES}

1. B.E. Hurless and F.H. Froes: Adv. Mater. Processes, 2002, vol. 160, pp. 37-40.

2. R. Grimes: Mater. Sci. Technol., 2003, vol. 19, pp. 3-10.

3. Y. Wang, J.N. Wang, and J. Yang: J. Alloys Compounds, 2004, vol. 364, pp. 93-98.

4. T.G. Nieh, J. Wadsworth, and O.D. Sherby: Superplasticity in Metals and Ceramics, Cambridge University Press, Cambridge, United Kingdom, 1997.

5. Y.V.R.K. Prasad, T. Seshacharyulu, S.C. Medeiros, and W.G. Frazier: J. Mater. Eng. Performance, 2000, vol. 9, pp. 153-60.

6. Y.V.R.K. Prasad, T. Seshacharyulu, S.C. Medeiros, and W.G. Frazier: J. Eng. Mater. Technol., 2001, vol. 123, pp. 355-60.

7. G.W. Greenwood and R.H. Johnson: Proc. R. Soc. London, 1965 vol. 283, pp. 403-22.

8. F.W. Clinard and O.D. Sherby: Acta Metall., 1964, vol. 12, pp. 911-19.

9. D. Oelschlagel and V.Weiss: Trans. Q. ASM, 1966, vol. 59, pp. $143-54$.

10. T.B. Massalski, S.K. Bhattacharyya, and J.H. Perepezko: Metall. Trans. A, 1978, vol. 9A, pp. 53-56.

11. J.D. Marvin and D.C. Dunand: Mater. Sci. Eng. A, 2006, vol. 421, pp. 35-39.

12. M. Jong and G.W. Rathenau: Acta Metall., 1961, vol. 9, pp. 714 20 .

13. P. Zwigl and D.C. Dunand: Mater. Sci. Eng. A, 1999, vol. 262, pp. 166-72.

14. M. Lozinsky: Acta Metall., 1961, vol. 9, p. 689.

15. K. Sato, T. Nishimura, and Y. Kimura: Mater. Sci. Forum, 1994 vol. 170-172, p. 207.

16. M. Frary, C. Schuh, and D.C. Dunand: Metall. Mater. Trans. A, 2002, vol. 33A, pp. 1669-80.

17. D.C. Dunand and P. Zwigl: Metall. Mater. Trans. A, 2001, vol. 32A, pp. 841-43.

18. C. Schuh and D.C. Dunand: J. Mater. Res., 2001, vol. 16 (3), pp. 865-75.
19. C. Schuh and D.C. Dunand: Acta Mater., 2001, vol. 49, pp. 199 210.

20. P. Zwigl and D.C. Dunand: J. Mater. Processing Technol., 2001, vol. 117 , pp. 409-17.

21. D.C. Dunand and S. Myojin: Mater. Sci. Eng. A, 1997, vol. 230, pp. 25-32.

22. P. Zwigl and D.C. Dunand: Metall. Mater. Trans. A, 1998, vol. 29A, pp. 2571-82.

23. K. Nuttall: Scripta Metall., 1976, vol. 10, pp. 835-40.

24. H.J. Gonzalez and D.C. Dunand: J. Mater. Eng. Performance, 2004, vol. 13, pp. 665-69.

25. M. Zamora and J.P. Poirier: Mech. Mater., 1983, vol. 2, pp. 193 202.

26. R.H. Johnson and G.W. Greenwood: Nature, 1962, vol. 195, pp. 138-39.

27. G.W. Greenwood and R.H. Johnson: React. Sci. Technol., 1962, vol. 16, p. 473.

28. D.C. Dunand and C.M. Bedell: Acta Mater., 1996, vol. 44, p. 1063.

29. C. Schuh and D.C. Dunand: Scripta Mater., 1999, vol. 40, pp. 1305-12.

30. C. Schuh and D.C. Dunand: Int. J. Plasticity, 2001, vol. 17, pp. $317-40$.

31. C. Schuh and D.C. Dunand: Scripta Mater., 2001, vol. 45, pp. 631-38.

32. C. Schuh and D.C. Dunand: Acta Mater., 1998, vol. 46, pp. 5663 75 .

33. F.U. Enikeev and A.A. Kruglov: Int. J. Mech. Sci., 1995, vol. 37, pp. 473-83.

34. A.R. Ragab: Met. Technol., 1983, vol. 10, pp. 340-48

35. Rodney Boyer, Gerhard Welsch, and E.W. Collings: Materials Properties Handbook: Titanium Alloys, ASM INTERNATIONAL, Materials Park, OH, 1994.

36. Metals Handbook, 9th ed., ASM INTERNATIONAL, Materials Park, OH, 1988, vol. 15 